\title{
Post-Traumatic Hydrocephalus - A Retrospective Study
}

\author{
R. Srinivas ${ }^{1}$, Davuluri Venkata Shashank ${ }^{2}$, Mohamed ${ }^{3}$ \\ 1,2,3 Department of Neurosurgery, Sri Ramachandra Institute of \\ Medical Sciences and Research, Chennai, Tamilnadu, India.
}

\section{ABSTRACT}

\section{BACKGROUND}

Post-traumatic hydrocephalus (PTH) can occur as an outcome of moderate and severe traumatic head injury. It is one of the causes of delayed worsening of the early symptoms of head injury. A total of 18 cases of PTH diagnosed and treated at tertiary care hospitals from 2012 to 2015 were studied. The purpose of the study was to evaluate the clinicoradiological profile of patients diagnosed with posttraumatic hydrocephalus and determine the outcome of ventriculoperitoneal (VP) shunting in cases of post-traumatic hydrocephalus.

\section{METHODS}

A retrospective study was conducted in the Department of Neurosurgery in a teaching medical college. The clinicoradiological profile of patients diagnosed with PTH was studied. These cases were treated conservatively as well as by surgery. The demography, cause of trauma, GCS score and response rates were studied.

\section{RESULTS}

Among the 18 reviewed patients, $61.1 \%$ were males, fall and RTA constituted the major cause of trauma. Craniotomy was done in $50 \%$ of the patients, $88.89 \%$ of the patients recovered and the mortality rate was $11.11 \%$.

\section{CONCLUSIONS}

Post-traumatic hydrocephalus is a consequence of traumatic head injury and can occur with various neurological symptoms after the initial trauma. CT scan of the brain is considered the choice of investigation to early diagnose PTH and the patient outcome after VP shunting is good.

\section{KEY WORDS}

Hydrocephalus, Head Injury, Trauma
Corresponding Author:

Dr. R. Srinivas,

Department of Neurosurgery,

Sri Ramachandra Institute of Medical

Sciences and Research,

Chennai, Tamilnadu, India.

E-mail: drsrinivas74@gmail.com

DOI: $10.14260 /$ jemds/2021/712

How to Cite This Article:

Srinivas $R$, Shashank DV, Naleer M. Posttraumatic hydrocephalus- a retrospective study. J Evolution Med Dent Sci 2021;10(40):3511-3514, 10.14260/jemds/2021/712

Submission 10-08-2021,

Peer Review 16-09-2021,

Acceptance 25-09-2021,

Published 04-10-2021.

Copyright (C) 2021 R. Srinivas et al. This is an open access article distributed under Creative Commons Attribution License [Attribution 4.0 International (CC BY 4.0)] 


\section{BACKGROUND}

Trauma is one of the most common causes of death in the first forty years of life. ${ }^{1}$ There is a wide range of posttraumatic sequelae of traumatic head injury. Traumatic brain injury is one of the leading causes of death and disability and has a high mortality rate ranging from 30 to $40 \% .^{2}$ The sequel of post-traumatic hydrocephalus (PTH) in head injury patients can occur weeks or even months after the initial trauma. PTH is a treatable complication of head injury and presents with variable clinical syndromes. Patients developing post-traumatic hydrocephalus present with neurological symptoms of varying severity. Post-traumatic hydrocephalus (PTH) has been documented since Dandy's report in $1914 .^{3}$ It is a common sequelae of traumatic brain injury. Previous studies in global literature have documented variable rates of incidence. ${ }^{4,5}$ The incidence range is wide $(0$ to $45 \%$ ) for PTH. ${ }^{6-9}$ This wide incidence is attributed to the varying diagnostic criteria followed worldwide. PTH is one of the main causes of deterioration in patients following traumatic brain injury. If left undiagnosed and untreated, PTH can produce a vegetative state in the patients and has a high mortality. 10

Recognition of PTH is very important to differentiate it from other causes of delayed deterioration like cerebral oedema, hypoxia, ischemia, electrolyte imbalance, seizures, and infection. PTH occurs due to excessive accumulation of cerebrospinal fluid (CSF) caused due to fluid-dynamic disturbances following traumatic head injury. ${ }^{11}$ This accumulation could be the result of overproduction or due to blockage in the drainage pathway of CSF or inadequate absorption leading to excessive accumulation. The management of PTH is aimed at reducing the intracranial pressure by relieving the excess CSF accumulated. This requires prompt timely diagnosis followed by invasive monitoring and timely therapy. The most common signs of PTH development in a patient with traumatic brain injury are sudden deterioration in vitals, vomiting, fundus examination shows papilledema. Post-traumatic hydrocephalus can be treated with a VP shunting procedure and can lead to a dramatic improvement in patient outcome. PTH is considered as "Cinderella without fairy godmother" of neurotrauma. ${ }^{12}$ Even though the incidence of PTH is high, there are very few articles available in the literature that describe the patient profile or the outcome of PTH following head injury. Only a few studies have mentioned the diagnosis and treatment modalities followed in PTH.13-16 When the lumbar CSF pressure is more than $180 \mathrm{~mm}$ of $\mathrm{H}_{2} \mathrm{O}$, surgery is indicated. Ventriculoperitoneal shunting (VP) is a standard procedure done in cases of PTH with elevated ICP. The CSF is redirected through a shunt for drainage in the peritoneal cavity. The shunt consists of a ventricular catheter that is placed inside the ventricle, which is in turn connected to a valve and finally connected to the distal catheter. The distal end of the VP shunt is brought down to the peritoneal cavity for CSF drainage. Recent advances in the medical devices sector have brought in shunts with fewer shunt malfunctions and blockage. ${ }^{17}$

The purpose of the study was to evaluate the clinicoradiological profile of patients diagnosed with post-traumatic hydrocephalus and determine the outcome of ventriculo- peritoneal (VP) shunting in cases of post-traumatic hydrocephalus.

\section{METHODS}

A retrospective study was done on 18 patients of PTH managed in a tertiary care hospital between 2012 and 2015 . All patients satisfying the selection criteria during the study period were included. Data of demographic profile, mode of injury, GCS and CT findings were retrieved from the database. Surgical or conservative management was documented. Clinical features were reported and radiological criteria of the presence of ventriculomegaly with periventricular lucencies in non-contrast CT scan was considered. This was done to eliminate ventriculomegaly caused due to loss of brain tissue (hydrocephalus ex-vacuo). Patients were treated with medium pressure ventriculoperitoneal shunts. Postoperative outcomes and complications were recorded.

\section{Statistical Analysis}

Head injury and type of injury were considered as primary explanatory variables and post-operative GCS and patient outcomes were considered as outcome variables. Descriptive statistics was done by frequency and percentage for all study variables. Bar charts and pie charts were used for the graphical representation of the data.

\section{RESULTS}

Data from 18 patients were analysed. A majority $(61.1 \%)$ were males and $38.88 \%$ belonged to the 50 to 60 years category. For post-traumatic hydrocephalus, conservative management was done in $28.89 \%$ of the patients and craniotomy was performed in $50 \%$ of patients. Road traffic accidents (RTA) (33.33\%) and fall (55.55\%) were the most common mode of trauma. The majority ( $50 \%$ ) had traumatic subarachnoid haemorrhage (SAH) on CT scans. Preoperative GCS ranged from 9 to 12 in a majority of the patients $(66.67$ $\%)$. Postoperative GCS ranged between 13 and 14 in $72.23 \%$ of the patients. Opening pressure on lumbar puncture was $13-15 \mathrm{~cm}$ of $\mathrm{H} 20$ in $55.5 \%$ of the patients. All $100 \%$ of the patients had CT features of hydrocephalus (Table 1). Among 18 patients, multiple symptoms were present such as headache, drowsiness, visual disturbance etc. (Figure 2). Among the 18 patients, 16 recovered completely and 2 died. (Figure 1).

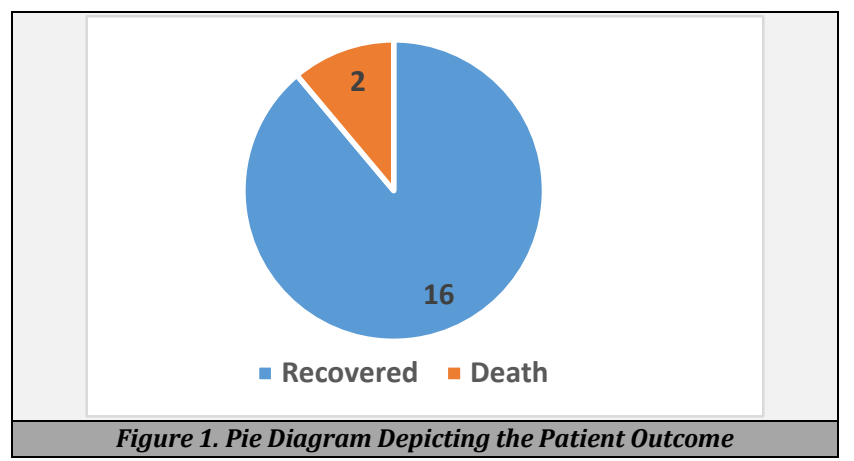




\begin{tabular}{|c|c|c|c|}
\hline $\begin{array}{l}\text { Sl. } \\
\text { No. }\end{array}$ & Parameters & Frequency & (\%) \\
\hline \multicolumn{4}{|c|}{ Sex } \\
\hline & Male & 11 & 61.1 \\
\hline & Female & 07 & 38.9 \\
\hline \multicolumn{4}{|c|}{ Age (in years) } \\
\hline & $30-40$ & 6 & 33.34 \\
\hline & $40-50$ & 5 & 27.78 \\
\hline & $50-60$ & 7 & 38.88 \\
\hline \multirow{2}{*}{\multicolumn{4}{|c|}{$\begin{array}{l}\text { Management of post-traumatic } \\
\text { hydrocephalus }\end{array}$}} \\
\hline & & 7 & 38.89 \\
\hline & Conservative & 9 & 50.00 \\
\hline & $\begin{array}{l}\text { Craniotomy } \\
\text { EVD }\end{array}$ & 2 & 11.11 \\
\hline \multicolumn{4}{|c|}{ Mode of injury } \\
\hline & RTA & 6 & 33.33 \\
\hline & Fall & 10 & 55.55 \\
\hline & Assault & 2 & 11.12 \\
\hline \multicolumn{4}{|c|}{ Type of injury on CT scan } \\
\hline & Contusion & 05 & 27.78 \\
\hline & Traumatic SAH & 09 & 50.00 \\
\hline & Traumatic IVH & 02 & 11.11 \\
\hline & Acute SDH & 02 & 11.11 \\
\hline \multicolumn{4}{|c|}{ Pre-operative GCS } \\
\hline & $14-15$ & 0 & 0 \\
\hline & $9-12$ & 12 & 66.67 \\
\hline & $3-8$ & 06 & 33.33 \\
\hline \multicolumn{4}{|c|}{$\begin{array}{l}\text { Opening pressure in lumbar puncture } \\
\left(\mathrm{cms} \mathrm{of} \mathrm{H}_{2} \mathrm{O}\right)\end{array}$} \\
\hline & $13-15$ & 10 & 55.55 \\
\hline & $16-17$ & 06 & 33.34 \\
\hline & $18-20$ & 2 & 11.11 \\
\hline & $20-25$ & 0 & 0 \\
\hline \multicolumn{4}{|c|}{ Post-operative GCS } \\
\hline & $13-14$ & 13 & 72.23 \\
\hline & $9-12$ & 5 & 27.77 \\
\hline & 3-8 & 0 & 0 \\
\hline & CT confirming hydrocephalus & 18 & 100 \\
\hline \multicolumn{4}{|c|}{$\begin{array}{l}\text { Table 1. Clinical Profile and Radiological Profile of } \\
\text { Study Participants }(N=18)\end{array}$} \\
\hline
\end{tabular}

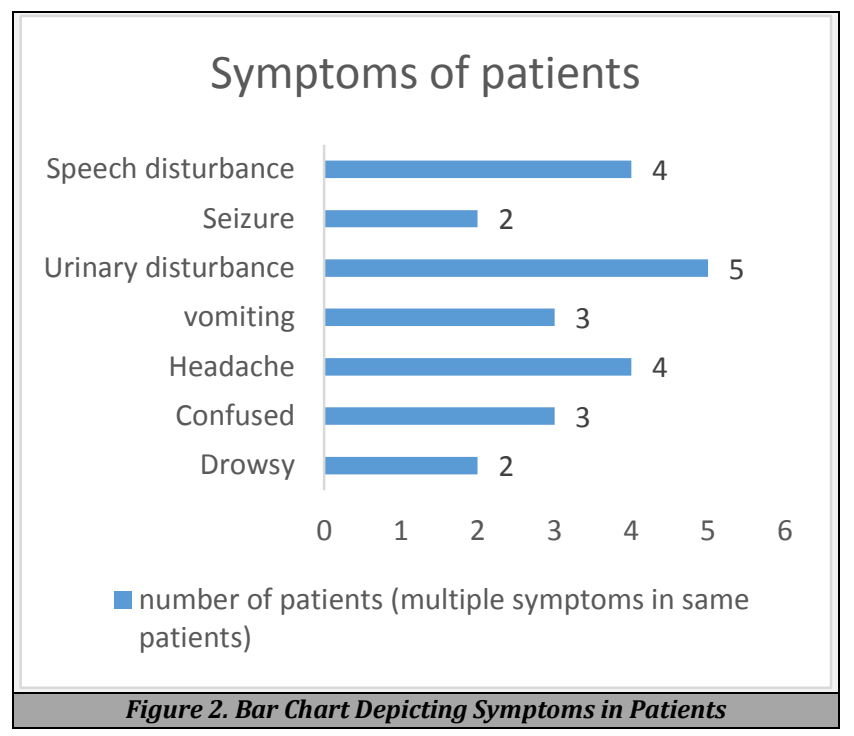

\section{DISCUSSION}

In the present study, a total of 18 cases with head injury developed post-traumatic hydrocephalus. In our study when a CT scan was done during the management of the patient ventriculomegaly and periventricular lucency were found in all the cases of post-traumatic hydrocephalus.

This study's results showed that post-traumatic hydrocephalus presents with different symptoms like altered sensorium, drowsiness, headache, vomiting, seizures, etc. Cardoso et al. suggested that post-traumatic hydrocephalus can present with varied clinical features such as altered sensorium, failure to improve, psychomotor hindrance, loss of memory, ataxic gait and urinary and anal incontinence..$^{4,18}$
Coma for a long duration or sudden deterioration in conscious patients should caution the development of hydrocephalus. In those patients, fundoscopy can be done which can reveal papilledema. ${ }^{19}$

In our study, the initial CT scan suggested various injuries. Contusion was the most common finding in our study. Traumatic SAH was the second most common pathology in our study. In some studies subarachnoid haemorrhage (SAH) has been mentioned as the most common cause that leads to the development of PTH.7,20-22

Hydrocephalus can occur in posttraumatic conditions. Based on this study's result, PTH was seen in young patients (younger than 40 years of age). This shows that it is need of the hour to use preventive programs to reduce the occurrence of trauma in this young productive age group. Since PTH is also observed in mild head injury, early diagnosis and timely treatment are warranted, thereby reducing hospital costs and long-term hospitalization. Future studies on long term follow up and large cohort studies are recommended.

\section{CONCLUSIONS}

Post-traumatic hydrocephalus is a consequence of traumatic brain injury and can occur with various neurological features after variable days of the initial trauma. CT scan is considered as the investigation of choice for early diagnosis of PTH and to rule out other possibilities of delayed deterioration in a recovering head injury patient. PTH has a very good outcome after VP shunting.

Data sharing statement provided by the authors is available with the full text of this article at jemds.com.

Financial or other competing interests: None.

Disclosure forms provided by the authors are available with the full text of this article at jemds.com.

\section{REFERENCES}

[1] Salimi J, Zavareh MN, Khaji A. Trauma mortality in six university hospitals: Tehran, Iran. Tehran Univ Med J 2007;65(Suppl 2):22-5.

[2] Majdan M, Plancikova D, Brazinova A, et al. Epidemiology of traumatic brain injuries in Europe: a cross-sectional analysis. Lancet Public Health 2016;1(2):e76-e83.

[3] Dandy WE, Blackfan KD. An experimental, clinical and pathological study. Am J Dis Child 1914;8(6):406-82.

[4] Cardoso ER, Galbraith S. Posttraumatic hydrocephalus a retrospective review. Surg Neurol 1985;23(3):261-4.

[5] Hawkins TD, Lloyd AD, Fletcher GIC, et al. Ventricular size following head injury: a clinico-radiological study. Clin Radiol 1976;27(3):279-89.

[6] Ding J, Guo Y, Tian H. The influence of decompressive craniectomy on the development of hydrocephalus: a review. Arq Neuropsiquiatr 2014;72(9):715-20.

[7] Choi I, Park HK, Chang JC, et al. Clinical factors for the development of posttraumatic hydrocephalus after decompressive craniectomy. J Korean Neurosurg Soc 2008;43(5):227-31. 
[8] Oi S. Classification of hydrocephalus: Critical analysis of classification categories and advantages of "multicategorical Hydrocephalus Classification" (Mc HC). Child's Nerv Syst 2011;27(10):1523-33.

[9] Cinalli G, Spennato P, Nastro A, et al. Hydrocephalus in aqueductal stenosis. Child's Nerv Syst 2011;27(10):1621-42.

[10] Weintraub AH, Gerber DJ, Kowalski RG. Posttraumatic hydrocephalus as a confounding influence on brain injury rehabilitation: incidence, clinical characteristics, and outcomes. Arch Phys Med Rehabil 2017;98(2):312-9.

[11] Olney MB. The diagnosis and surgical treatment of tetralogies. Calif Med 1949;70(6):453-8.

[12] De Bonis P, Anile C. Post-traumatic hydrocephalus: the cinderella of neurotrauma. Expert Rev Neurother 2020;20(7):643-6.

[13] Marmarou A, Foda MA, Bandoh K, et al. Posttraumatic ventriculomegaly: hydrocephalus or atrophy? A new approach for diagnosis using CSF dynamics. J Neurosurg 1996;85(6):1026-35.

[14] De Bonis P, Mangiola A, Pompucci A, et al. CSF dynamics analysis in patients with post-traumatic ventriculomegaly. Clin Neurol Neurosurg 2013;115(1):49-53.
[15] De Bonis P, Tamburrini G, Mangiola A, et al. Posttraumatic hydrocephalus is a contraindication for endoscopic third-ventriculostomy: Isn't it? Clin Neurol Neurosurg 2013;115(1):9-12.

[16] Ramesh VG, Narasimhan V, Balasubramanian C. Cerebrospinal fluid dynamics study in communicating hydrocephalus. Asian J Neurosurg 2017;12(2):153-8.

[17] Hauk L. Ventriculoperitoneal shunt. AORN J 2018;107(1):P10-2.

[18] Beyer B Black PM. Posttraumatic hydrocephalus. Neurosurgery 1984;15(2):257-61.

[19] Jiao QF, Liu Z, Li S, et al. Influencing factors for posttraumatic hydrocephalus in patients suffering from severe traumatic brain injuries. Chinese J Traumatol English Ed. 2007;10(3):159-62.

[20] Tian HL, Xu T, Hu J, et al. Risk factors related to hydrocephalus after traumatic subarachnoid hemorrhage. Surg Neurol 2008;69(3):241-6.

[21] Licata C, Cristofori L, Gambin R, et al. Post-traumatic hydrocephalus. J Neurosurg Sci 2001;45(3):141-9.

[22] Waziri A, Fusco D, Mayer SA, et al. Postoperative hydrocephalus in patients undergoing decompressive hemicraniectomy for ischemic or hemorrhagic stroke. Neurosurgery 2007;61(3):489-93. 